\title{
PHOTOMETRIC MONITORING OF BINARIES IN OPEN CLUSTERS AND ASSOCIATIONS: NGC 6231
}

\author{
C. Sterken ${ }^{1}$ and M. Y. Bouzid ${ }^{1}$ \\ RESUMEN
}

Durante el último par de años hemos llevado a cabo observaciones CCD a largo plazo de cúmulos abiertos y asociaciones con el objetivo principal de detectar y estudiar estrellas pulsantes. Un producto secundario de este proyecto es una colección variada de fotometría multicolor de las binarias compactas más interesantes que presentan señales de actividad, o sea, períodos variables y curvas de luz fuertemente variables. Esta presentación ilustra el proyecto y se concentra en curiosas especies de binarias en interacción en NGC 6231.

\section{ABSTRACT}

Over the last couple of years we carried out long-term CCD monitoring of open clusters and associations with as principal goal the detection and study of pulsating stars. A by-product of this project is the serendipitous collection of multicolour photometry of most interesting compact binaries which show signs of activity, viz. variable periods and strongly variable light curves. This presentation illustrates the project, and concentrates on intriguing species of interacting binaries in NGC 6231.

\section{Key Words: GALAXY: OPEN CLUSTERS AND ASSOCIATIONS: INDIVIDUAL (NGC 6231) - STARS: VARIABLES}

\section{INTRODUCTION}

Over the last couple of years we carried out longterm CCD monitoring of open clusters and associations with as principal goal the detection and study of pulsating stars (in particular $\beta$ Cephei and $\delta$ Scuti stars, but also Be stars). A by-product of this project is the serendipitous collection of multicolour photometry of most interesting compact binaries which show signs of activity, viz. variable periods and stronglyvariable light curves.

The Scorpius Centaurus association is the OB association nearest to the Sun $(200 \mathrm{pc})$, a richly populated star-forming region that extends from Scorpius to Crux. It contains several open clusters, among which the nearby clusters Trumpler 24 and NGC 6231. A search for variables in $\operatorname{Tr} 24$ was undertaken by R.E. Mennickent and C. Sterken, and led to the discovery of 21 new variable stars, including 3 eclipsing binaries (see Fu et al. 2003a, 2003b).

NGC $6231\left(\alpha_{2000}=16^{\mathrm{h}} 54^{\mathrm{m}}, \delta_{2000}=-41^{\circ} 50^{\prime}\right)$ is one of the youngest galactic open clusters, located in the nucleus of association Sco OB1. In an ongoing effort to map and study the variability in NGC 6231, Sterken et al. (2002) presented new results based on CCD time-series data which were obtained at ESO during multiple observing campaigns at the Danish 1.54-m telescope (Strömgren uvby system).

\footnotetext{
${ }^{1}$ Vrije Universiteit Brussel, Pleinlaan 2, 1050 Brussel, Belgium.
}

\section{MONITORED BINARIES IN NGC 6231}

We use the identifications of Sung et al. (1998). SBL 574 [Se230] $(V=12.46)$ and SBL $314(V=$ $9.29)$ are two new eclipsing binary systems.

SBL 521 [Se232;SAAO040] ( $V=9.71)$ was observed first by Balona and Engelbrecht (1985) but no orbital parameters were derived. We observed a descending branch in July 2000 and a rising branch in March 2001.

Struve (1944) was the first who suspected the binarity of SBL 505 [Se224;SAAO100] $(V=8.23)$, and Hill et al. (1974) made the first estimation of the pe$\operatorname{riod} P=2.446 \pm 0.005$ days. Garcia and Mermilliod (2001), on the basis of spectroscopic observations. found a period of $2.45 \mathrm{~d}$. SBL 505 was classified by Levato and Morrell (1983) as an O9 IV binary, but recently it was shown to be a O9 III + B1 III by Sana et al. (2003). The period $P=2.44070 \mathrm{~d}$ obtained by these authors, however, leads to a better fit (see Figure 1). SBL 505 is the second known SB2 eclipsing binary of NGC 6231 .

The observations in the Strömgren $b$ and $y$ filters almost fully cover all phases, and are the first available complete light curves of this detached but relatively close system. The light curves obtained in these four bands vividly indicate signs of activitr. viz. strong cycle-to-cycle variability and possibly a variable period. 

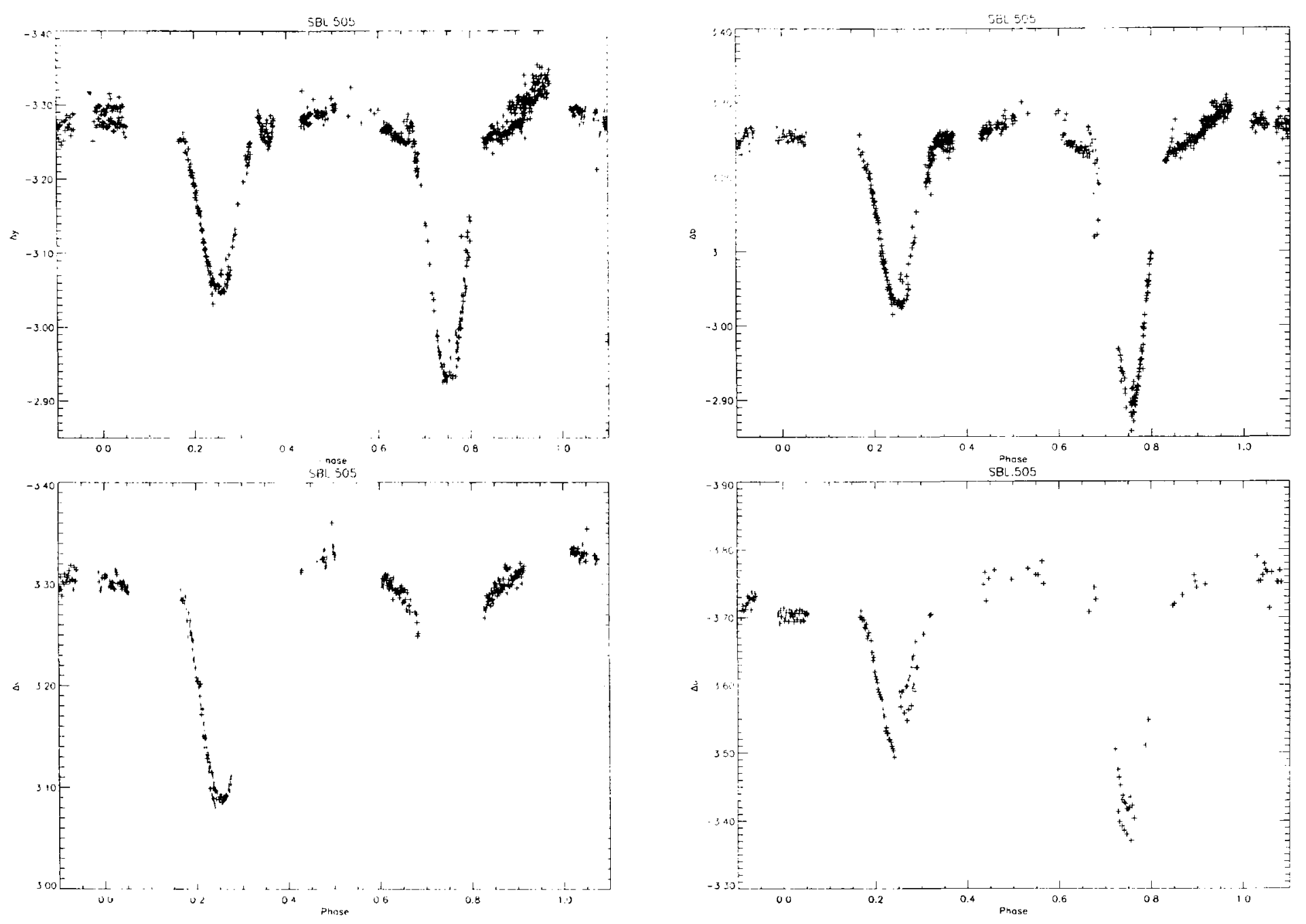

Fig. 1. Differential light curves of SBL 505 in $y$ and $b$ (top) and $v$ and $u$ (bottom) for July 2000 and March 2001.

This work has been supported by "IUAP P5/36" Interuniversity Attraction Poles Programme of the Belgian Federal Office for Scientific, Technical and Cultural Affairs, and the Belgian Fund for Scientific Research (FWO).

\section{REFERENCES}

Balona L. A., Engelbrecht C. A. 1985, MNRAS, 212, 889 Fu, J. N., Duerbeck, H. W., Sterken, C. and Mennickent, R. E. 2003a, in Interplay of Periodic, Cyclic and Stochastic Variability in Selected Areas of the H-R Diagram, Ed. C. Sterken, ASP Conf. Ser. 292, p. 45

Fu, J. N., Duerbeck, H. W., Sterken, C. and Mennickent, R. E. 2003b, AA 41297
Garcia, B., Mermilliod, J. C. 2001, A\&AS, 122, 136

Hill, G., Crawford, D. L., Barnes, J. V., 1974, AJ79, 1271

Levato, H., Morrell, N. 1983, ApL 23, 183

Sana, H., Hensberge, H., Rauw, G. 2003, A\&A, 1063, 1074

Sana, H., Rauw, G., Gosset, E. 2001, A\&A, 370, 121

Sterken, C., Knudsen, M. R., Duerbeck, H. W., Arentoft, T., Freyhammer, L. M., Pompei, E., Delahodde, C. E., Cortes, J., Clasen, J. W., Nuspl, J. 2002, in Observational Aspects of Pulsating B- and A Stars, ASP Conference Proceedings, Vol. 256. Ed. C. Sterken and D. W. Kurtz, p. 183.

Struve, O., 1944, ApJ100, 189

Sung, H., Bessell, M. S., Lee, S.-W. 1998, AJ115, 734 (SBL)

Vrije Universiteit Brussel, Pleinlaan 2, 1050 Brussel, Belgium (csterken@vub.ac.be,ybouzid@vub.ac.be). 